\title{
Royal College of Ophthalmologists: National Survey of ST1 Supervision
}

\author{
Christopher King ${ }^{1} \cdot{\text { Alex } \text { Tytko }^{2} \cdot \text { Anne Fiona Spencer }}^{2,3,4} \cdot$ Anna Mead $^{5}$
}

Received: 20 September 2018 / Accepted: 19 November 2018 / Published online: 7 January 2019

(c) The Royal College of Ophthalmologists 2019

Ophthalmology trainees often have minimal ophthalmology experience before starting ST1. Balancing adequate trainee supervision with service provision is challenging for hospital trusts and with the rising demand on acute ophthalmic services this is an increasing problem [1]. At the time of the survey in 2017 there was no national guideline for the level of supervision required for ST1s in acute and emergency settings.

We set out to identify the practices of ST1 supervision in acute and emergency settings across all ophthalmic units in the UK, assess how the differing levels of supervision are perceived by trainees and by college tutors, and to determine the level of oversight of heads of schools.

The authors wrote three surveys, approved by the RCOphth Chair of Training: one directed to ST1 and ST2 trainees to answer on the basis of their ST1 experience, a second to college tutors and a third to heads of schools. The surveys were circulated by the college with an e-mail link to Survey Monkey in January 2017 and were re-circulated to non-responders. Ninety nine responses were received from trainees; 53 ST1s and 46 ST2s were representing 64 trusts across 20 deaneries. Sixty three responses were received from college tutors from 57 trusts across 21 deaneries. Fourteen responses were received from heads of schools.

Christopher King

cjking@cantab.net

1 Oxford Eye Hospital, John Radcliffe Hospital, Oxford University Hospitals NHS Foundation Trust, Oxford, UK

2 Royal College of Ophthalmologists, London, UK

3 Manchester Royal Eye Hospital, Manchester University NHS Foundation Trust, Manchester, UK

4 Faculty of Biology. Medicine and Health, University of Manchester, Manchester Academic Health Science Centre, Manchester, UK

5 Buckinghamshire Healthcare NHS Foundation Trust, Aylesbury, UK
Chart 1 Compares the trainee-reported supervision levels in Eye Casualty and out-of-hours $(\mathrm{OOH})$ at the beginning of ST1. Forty percent of trainees reported having felt unsupported in Eye Casualty or $\mathrm{OOH}$.

Table 1A compares the mean scores given by trainees and college tutors to their perceived level of safety in both Eye Casualty and $\mathrm{OOH}$ with 1 being extremely dangerous and 10 being completely safe. Table $1 \mathrm{~B}$ compares the mean scores given by trainees and college tutors to their perceived adaptation of supervision in both Eye Casualty and $\mathrm{OOH}$ with 1 being no adaptation and 10 being specifically tailored to individuals.

Forty one percent of trainees reported working $\mathrm{OOH}$ from the start of ST1. Where OOH working was delayed this varied between 2 weeks to 1 year. Heads of schools had no clear consensus on expected levels of supervision in Eye Casualty or on-call. Many heads of School were not confident in knowing the ST1 supervision in arrangements of their units with $36 \%$ reporting to know the exact arrangements for Eye Casualty and 29\% for $\mathrm{OOH}$.

Table 1 (A) Scores for perceived safety; (B) scores for perceived adaptation of supervision

\begin{tabular}{llll}
\hline & Eye casualty & Out-of-hours & $p$-value \\
\hline $\begin{array}{l}\text { A: Safety scores } \\
\text { Trainees }\end{array}$ & Mean 7.763 & Mean 6.827 & 0.0007 \\
& SD 1.902 & SD 1.649 & \\
College tutors & Mean 8.512 & Mean 7.971 & 0.0516 \\
& SD 1.099 & SD 1.317 & \\
p-value & 0.0177 & 0.0004 & \\
B: Adaptation of supervision & & \\
Trainees & Mean 6.559 & Mean 6.000 & 0.1822 \\
& SD 2.776 & SD 2.711 & \\
College tutors & Mean 7.465 & Mean 7.400 & 0.9193 \\
& SD 2.594 & SD 2.681 & \\
$p$-value & 0.0732 & 0.0117 & \\
\hline
\end{tabular}



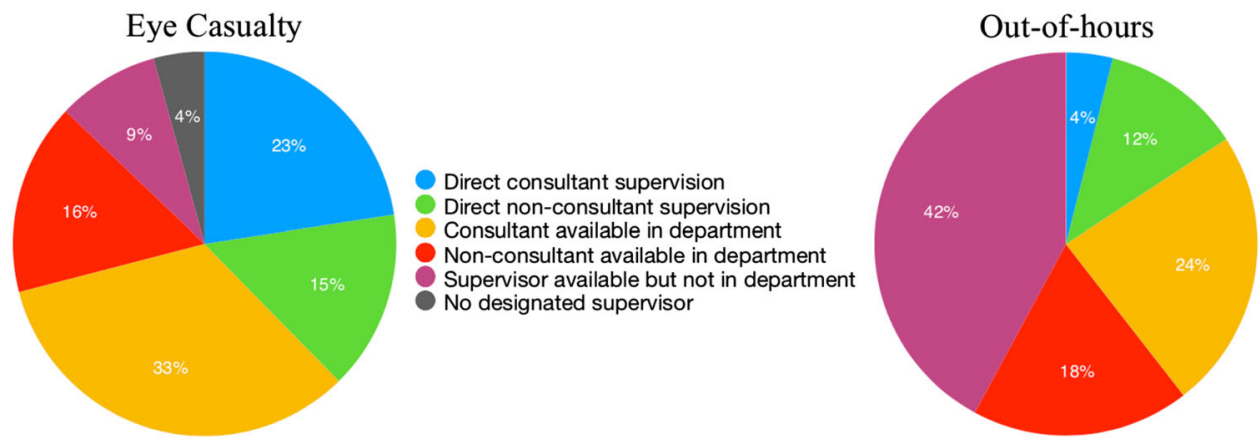

Chart 1 Comparison of supervision levels

Trainees report significantly lower safety scores in Eye Casualty and $\mathrm{OOH}$ than college tutors and a significant and more marked difference in the safety of $\mathrm{OOH}$ supervision. Trainees also report lower adaptation of supervision to individuals, especially $\mathrm{OOH}$. There is marked variation between units and heads of schools in levels of ST1 supervision and often limited oversight from heads of schools in local arrangements.

Following this survey, the college has produced new guidelines on Acute Services Training [2], which provides guidance for units on managing acute services with junior trainees.

\section{Compliance with ethical standards}

Conflict of interest AFS has received honoraria for delivering lectures/ teaching/patient information videos and received sponsorship for travel and accommodation for scientific meetings from Alcon, Allergan, Thea and Santen; has been a member of an Advisory Board for Visupharma; and has recently been a co-investigator receiving research funding from the College of Optometrists. The remaining authors declare that they have no conflict of interest.

Publisher's note: Springer Nature remains neutral with regard to jurisdictional claims in published maps and institutional affiliations.

\section{References}

1. The Way Forward: Emergency Eye Care. Royal College of Ophthalmologists, 2015. https://www.rcophth.ac.uk/wp-content/ uploads/2015/10/RCOphth-The-Way-Forward-Emergency-Eye-Ca re-300117.pdf.

2. Resources and Support for Trainees: Acute Services Training. Royal College of Ophthalmologists, 2017. https://www.rcophth.ac. uk/wp-content/uploads/2017/11/Acute-Services-Training.pdf. 